\title{
MOLECULAR CHARACTERIZATION OF PHOSPHOLAMBAN AND RENINANGIOTENSIN SYSTEM GENES MUTATIONS AND CLINICAL EPIDEMIOLOGY IN HUMAN CARDIOMYOPATHY
}

2 Gnana Veera Subhashini ${ }^{1 *}$, Beesetti Swarna latha ${ }^{1}$, Mavuluri Jayadev ${ }^{1}$, Emmanuel $^{2}$, K M Cherian²

1. Baba Clinical and Genomic Research Centre, Chennai 600113, Tamilnadu, India.

2. International Center for Cardio Thoracic and Vascular Diseases, Frontier Lifeline,

7

\section{ABSTRACT}

\section{Background}

\section{Methods} Chennai, India.

* Correspondence: Dr. N. Gnana Veera Subhashini Email Id: dr.ngvsubhashini@bcgrc.com

Cardiomyopathy is commonly observed disease that may occurs due to mutations in either susceptible genes or modifier gene. People with broad age group are affected either attributable to spontaneous or inherited mutations of these genes. Various gene mutations are reported so far but only few of them were studied in detail. 
In the current study, we evaluated epidemiological variables like age, sex, familial status, parental consanguinity. We also described specific clinical symptoms associated with the cardiomyopathy condition in Indian population.

\section{Results}

Our studies on mutation screening of phospholamban gene revealed two transitions (4880 C/T, $4887 \mathrm{~T} / \mathrm{G})$ in 5' flanking region which might cause inherited dilated cardiomyopathy with refractory congestive heart failure are We further deliberated the gene polymorphism of renin angiotensin system gene angiotensin-1-converting enzyme as an associated marker/ modifier in cardiomyopathy patients and their family members.

\section{Conclusions}

Information on epidemiological, clinical statistics, phospholamban gene mutation analysis and angiotensin-1-converting enzyme gene polymorphism is essential to guide the successful execution for future therapies and benefits us to identify those patients at risk for faster disease progression, congestive heart failure, and arrhythmia.

Keywords: Cardiomyopathy, Hemodynamic and Biochemical Parameters,

Epidemiological and clinical Parameters, Phospholamban Angiotensin-1-converting enzyme.

\section{INTRODUCTION}

8 In the present scenario, the debilitating nature of cardiovascular disorder is alarming and

9 needs a constant watch on the premature morbidity and mortality status. Cardiomyopathy

is the heart muscle disease and most common genetic disease of the heart, characterized 
41 by heterogeneous morphologic expression and clinical condition (1). It can manifest negligible to extreme hypertrophy, minimal to extensive fibrosis, myocyte disarray, absent to severe left ventricular outflow tract obstruction, distinct septal morphologies, or hypocontractile (2). Cardiomyopathy can cause heart failure (HF), which in most cases leads to sudden cardiac death (SCD). Hypertrophic Cardiomyopathy (HCM), Dilated Cardiomyopathy (DCM), Restrictive Cardiomyopathy (RCM) and Arrhythmogenic Right Ventricular Cardiomyopathy (ARVC) are four types of cardiomyopathies reported (3). These types can be primary myocardial disorders or at times develop as a secondary consequence of a variety of conditions viz., myocardial ischemia, inflammation, viral infection, increased myocardial pressure or volume load, and toxic agents (4). The etiology of both HCM and DCM involve cardiac energy imbalances and the clinical expressions of them are based on the addictive factors that are involved in it.

The prevalence of the dilated cardiomyopathy has formerly been estimated at $36.5 / 100,000$, with an incidence of $4-8 / 100,000$ persons-year (5). An echocardiographic analysis of 4111 subjects in CARDIA study by (6) revealed hypertrophic cardiomyopathy affects 1 in 500 people, a prevalence similar to familial hypercholesterolemia. Recent study estimates prevalence of dilated and hypertrophic Cardiomyopathy as 36 cases per 100,000 people and $10-20$ cases per 100,000 people respectively (7). Most of the dilated Cardiomyopathy cases are sporadic; although 20$35 \%$ of them are familial (8). The incidence of dilated cardiomyopathy varies in men and women. However, in general, heart failure is more common in men (9). The treatment arm of the Studies on Left Ventricular Dysfunction (SOLVD), in which only $15 \%$ of the 
patients were women, reported no sex-related difference in survival in either the placebo group or the Enalapril group $(10,11)$. Age distribution depends on prognosis, diagnosis or onset of any underlying disease. However, advancing age is reported as an independent risk factor for mortality in several studies (12).

Phospholamban (PLN) is a small transmembrane phosphoprotein of 52 amino acids that plays an important role in cardiac contraction and relaxation. Phospholamban, expressed in the sarcoplasmic reticulum membrane controls cellular calcium levels by a mechanism that depends on its phosphorylation (13). The human ventricle and quadriceps displayed high levels of phospholamban transcripts and proteins (14), whereas lower expression in smooth muscles and right atrium. DCM patients with a phospholamban gene mutation have a chronically inhibited Ca2+- ATPases pump, which leads to DCM in their teenage $(15,16)$

Susceptibility genes have a role in the development of cardiomyopathies, whereas modifier genes have a role in the evolution or prognosis of the disease. In most studies due to limited sample sizes, the role of susceptibility and modifier genes have been only suggestive (17). Various genes underlying cardiomyopathy have been identified from linkage as well as candidate gene studies, and include those coding for proteins involved in the cytoskeleton, the Z-disk, the nuclear envelop, ion conduction and calcium handling proteins (18). This variability in expression of these causal genes is also seen among family members sharing the same mutation. This variable expressivity, which confuses genotype/phenotype correlations, could be partially explained by both environmental influences and genetic modifiers (19). The angiotensin-1-converting enzyme (ACE) polymorphism has been commonly studied with variable results. It's noteworthy to study 
and understand the importance of modifier genes. The genetic polymorphisms of the renin-angiotensin-aldosterone system (RAAS) are found to influence the progression to cardiac disorders (20). Angiotensin-1-converting enzyme (ACE), a modifier gene was perceived to have insertion/Insertion (I/I) genotype associated with low serum ACE activity levels, Insertion/Deletion (I/D) genotype with intermediate levels and Deletion/Deletion (D/D) high serum ACE activity levels. The effect of ACE polymorphism on survival in patients with DCM with a DD genotype had poorer prognosis than other genotypes (5-year survival rate 49 vs.72\%, p=0.001) (21). The DD genotype was also associated with an increase in left ventricular mass (22).

The present study investigates the association of spectrum of clinical symptoms, the epidemiological variables like age, sex, familial status, parental consanguinity and the mutations in the gene encoding phospholamban cardiac protein and to establish the genotype - phenotype correlations, to identify the modes of inheritance and the risk stratification in a group of clinically well characterized patients and their relatives associated with the cardiomyopathy condition in Indian population. We further studied the role of angiotensin-1-converting enzyme gene polymorphism as an associated marker/ modifier in cardiomyopathy patients and their family members.

\section{MATERIALS AND METHODS}

\section{STUDY SUBJECTS}


109 A total of 109 unrelated index cardiomyopathy patients and their family members who

110 were consecutively enrolled in cardiology units of the Government General Hospital,

111 Chennai and International Center for Cardiothoracic and Vascular Diseases (ICCTVD),

112 Dr. K.M. Cherian Heart Foundation, A unit of Frontier lifeline, Chennai, South India, were

113 included in the present study. A panel of 100 age matched healthy control subjects with

114 no history of heart disease was obtained. The study protocol was approved by the

115 Institutional Review Board and a Written consent was obtained from all subjects in

116 accordance with the Institutional Ethical committee human subject guidelines.

\section{CLINICAL EVALUATION}

119 The index cases were subjected to standard physical examinations, clinical

120 evaluations, electrocardiographic and echocardiograph tests to confirm cardiomyopathy.

121 Cardiomyopathy was diagnosed based on the presence of the following; dilated cardiomyopathy with Left ventricular ejection fraction (LVEF) $<45 \%$ and left ventricular end diastolic diameter $>27 \mathrm{~mm} / \mathrm{m} 2$. However, patients who had secondary cause were not included in the present study. Further, hypertrophic cardiomyopathy was confirmed by LV wall thickness $\geq 15 \mathrm{~mm}$ and blood pressure $\leq 160 / 100 \mathrm{mmHg}$. Demographic and clinical information (Echocardiographic and Electrocardiographic findings) have been

127 taken from the case sheets of respective hospitals. Family history and parental 128 consanguinity were collected from the patients. Patients were classified according to New

129 York Heart Association (NYHA) and exercise capacity has also been taken.

\section{BLOOD SAMPLE COLLECTION}


132 Five milliliters of peripheral blood were drawn in EDTA coated vacutainer

133 from patients, family members and control subjects and stored at $4^{\circ} \mathrm{C}$ until DNA 134 extraction.

\section{DATA COLLECTION}

137 Epidemiology parameters such as height, weight, sex, age at onset, dietary

138 habits, addictions to smoking and alcohol were collected during personal and clinical

139 history. Each of the subjects met the Clinical diagnostic criteria viz., 12 lead

140 electrocardiograms, echocardiogram, clinical symptoms, risk factors, medication and

141 outcome of the disease etc.

\section{CLINICAL CHEMISTRY PARAMETERS:}

145 Blood parameters like sugar, urea, creatinine, creatinine phosphokinase (CpK), atrial 146 natriuretic peptide (ANP), brain natriuretic peptide (BNP), serum aspartate transaminase 147 (SGOT) and Serum alanine transaminase (SGPT) were analyzed using DaytonaRM 148 Randox auto analyzer according to the manufacturers' instructions.

151 In the present study, the index cases are categorized into two groups viz., familial case

152 showing the incidence of the disease in first and second-degree relatives and in sporadic

153 cases lack of any familial incidence, presumably non- genetic in origin. The present study 
examined a comprehensive screening of Phospholamban and a key determinant/modifier angiotensin-1-converting enzyme gene polymorphism.

\section{DNA ISOLATION and QUANTIFICATION}

Genomic DNA was extracted from the peripheral blood following the protocol of (23). Briefly, the collected blood was mixed with an equal volume of TKM1 buffer (10mM Tris- $\mathrm{HCl}, 10 \mathrm{mM} \mathrm{KCl}, 10 \mathrm{mM} \mathrm{MgCl}_{2}$ and $2 \mathrm{mM}$ EDTA) and $100 \mu \mathrm{l}$ Triton $\mathrm{X}$. The contents were centrifuged and the pellet was washed with TKM1 repeatedly until the cell debris is washed out. The pellet is suspended in $800 \mu$ of TKM2 solution (10mM Tris$\mathrm{HCl}, 10 \mathrm{mM} \mathrm{KCl}, 10 \mathrm{mM} \mathrm{MgCl}_{2}, 2 \mathrm{mM}$ EDTA and $0.4 \mathrm{M} \mathrm{NaCl}$ ) followed by centrifugation and precipitation of the supernatant in ethanol. The DNA samples were then stored at $-20^{\circ} \mathrm{C}$ for subsequent analyses. The DNA was quantified using spectrophotometer. The DNA was diluted in TE to yield 50ng/ $\mu$ l concentration.

\section{PHOSPHOLAMBAN (PLN) POLYMERASE CHAIN REACTION}

The primers of the hotspots exons of Phospholamban (PLN) forward primer 5'tattttctcataattaaaattcctgc-3' and reverse primer 5'-aaagtaagaattaccaaagtcagcg-3' for Exon 1 and forward primer 5'-aacaatagtgctgaggaagatgaa-3' and reverse primer 5'ttgttttcctgtctgcatgg-3' for Exon 2 were used (24).

\section{ANGIOTENSIN-1-CONVERTING ENZYME GENOTYPING}

The primers of the hotspots exons of the Angiotensin-1-Converting Enzyme (ACE) forward primer 5'-tattttctcataattaaaattcctgc-3' and reverse primer 5'- 
aaagtaagaattaccaaagtcagcg-3' were used (25). Angitensin-1-converting enzyme genotyping was based on amplification of genomic DNA by PCR and the products were detected on $2 \%$ agarose gel. Amplification products $490 \mathrm{bp}$ and $190 \mathrm{bp}$ corresponding to the I and D alleles respectively (26).

\section{DNA SEQUENCING}

Genomic DNA from individuals with different SSCP patterns was amplified and sequenced with using Applied Biosystems 3730xI DNA Analyzer. The sequencing PCR was carried on 96 well micro-titer plates in a $5 \mu$ reaction volume containing nuclease free water, the amplified template, "BigDye" (fluorescently labeled ddNTPs, dNTPs) and primers. The amplified DNA was precipitated by incubating at room temperature with $25 \mu \mathrm{l}$ of $3 \mathrm{M}$-sodium acetate in ethanol $(120 \mu \mathrm{l}$ of $3 \mathrm{M}$-sodium acetate in $3 \mathrm{ml}$ of $100 \%$ ethanol) for $15 \mathrm{~min}$. The DNA was made single stranded by adding Hi-Di Form amide and sequenced on $A B|3730 x|$ automated DNA analyzer. The chromatograms obtained were analyzed on "Auto assembler" chromatogram analyzer on a Macintosh operating system. Complete sequencing work was carried out at the "Center for Cellular and Molecular Biology" Hyderabad.

\subsection{BIOINFORMATICS}

Multiple Sequence Analysis (MSA) was used for sequence comparison between generated sequences of the present study and to the corresponding reference sequences obtained from GenBank. The generated gene sequences were translated as protein sequences for future analysis (EXPASY Tool). Using Conserved Domains Database and 
200 Motif Finder Database alteration in the conserved domains and motifs as a consequence

201 of mutation were identified for the generated sequences.

202

\subsection{STATISTICAL ANALYSES}

Statistical analyses were carried out using Statistical Analysis Solutions (SAS 9.2). The mean and standard deviation were computed for various quantitative parameters and calculated. P-value < 0.05 was considered significant. Association and relative risk estimates were carried out using Chi square test for the qualitative parameters at $1 \%$ and $5 \%$ levels of significance. The Allele frequencies were computed by gene counting method. Departure from Hardy- Weinberg equilibrium was tested by chi-square test. The odds ratio was computed using SAS.

\section{RESULTS}

\section{EPIDEMIOLOGICAL STUDY}

\section{Patients and Baseline Characteristics}

217 A total of 109 unrelated index patients who have echocardiographically and 218 electrocardiographically assessed for cardiomyopathy and 100 aged matched control 219 subjects were studied. About 73 percent of the patients had dilated cardiomyopathy and 22027 percent hypertrophic cardiomyopathy. Details on age, body mass index, blood 221 pressure, blood biochemical profile, associated clinical and non-clinical features of the 222 patients, control subjects were given in (Table 1). Males were significantly higher among 
223 the patients $(73 \%)$. The mean age of all patients was $37.22 \pm 12.43$ years. Occurrence

224 was familial in $24 \%$ of cases, but sporadic in the other $76 \%$ of patients. In patients group 225 about $30 \%$ of them had family history of sudden cardiac death and $14 \%$ of them showed 226 parental consanguinity. Mean value of body mass index and body surface area was same 227 in patients and control $(p=0.085, p=0.515)$.

\section{Hemodynamic and Biochemical Parameters}

230 Diastolic blood pressure, heart rate and systolic blood pressure of cardiomyopathy 231 patients was extremely significant when compared with the control subjects $(p<0.05)$. 232 Cardiomyopathy patients were characterized with high atrial natriuretic peptide (ANP) and brain natriuretic peptide (BNP) level $(p<0.001)$. Contrastingly creatinine phosphokinase (CpK), serum aspartate transaminase (SGOT), serum alanine transaminase (SGPT), glucose, urea and creatinine levels did not show much variation between patients and control group (Table 1). Similarly, co-morbid factors such as diabetes, obesity, smoking and alcoholism did not show any influence on patient population.

\section{CLINICAL CHARACTERISTICS}

The electrocardiographic and echocardiographic characteristics of the cardiomyopathic

241 patients and control group were given in Table 2. All comparisons were significant

242 between cardiomyopathic patients and control $(p<0.001)$ except fractional shortening, left

243 ventricular ejection fraction, outflow tract gradient, early to late (E/A ratio) trans mitral flow 244 velocity, and left ventricular systolic and diastolic volume. 


\section{MOLECULAR ASPECTS}

\section{Phospholamban Gene Mutation}

250 Phospholamban gene is located on chromosome 6q22.1. Genomic sequence of the gene is 12146 bps nucleotides long which encodes 1742 bps mRNA coding region comprises 159 bps which encodes 2exons. The protein is a pentamer and is a major substrate for cAMP-dependent protein kinase in the cardiac muscle. The protein inhibits Ca2+-ATPase in unphosphorylated state. The protein is a key regulator of cardiac diastolic function. Table 3 shows the detailed description of the mutations in phospholamban gene. Seven 256 mutations -two in the 5' flanking region, two in exon 1 and three in the intron1 region 257 (Figure 1 (a-f)). Transition T/G in 4887 nucleotide regions of 5' flanking region was observed in two HCM probands with four affected family members and also in one dilated cardiomyopathic proband with no affected relatives. 15511-15512 insertion T was observed in one dilated cardiomyopathic proband with 2 affected family members and one dilated cardiomyopathic proband with no affected family members.

\section{Description of Familial Condition} 4887(T/G) mutation:

265 In the pedigree of the H9 proband (male, 21years) (Figure 2), the proband's father and 266 his two uncles died young of sudden cardiac arrest. The younger brother of the proband's 267 father has an affected son. The mutation was in heterozygotic state and it is not observed 268 in unaffected. 
269 In the pedigree of $\mathrm{H} 10$ proband (Figure 3 ), the $\mathrm{T}$ to $\mathrm{G}$ transition was observed in two 270 family members The H10 proband (Male, age: 41years) had an affected offspring who

271 was deceased subsequently to this study. The proband's parents are consanguineous 272 and his mother died of cardiac arrest. The proband's brother had also carried this mutation 273 and his daughter died unexpectedly at the age of 18 years.

27415512 ins T mutation:

275 The intronic mutation in PLN gene was observed in one dilated cardiomyopathy patient 276 and in his family members (Figure 4). The D15 proband (Male, age: 37 years) who carried 277 this mutation has an affected father (66 years). The proband's father's brother died of 278 sudden cardiac arrest at the age of 22 years. The mutation in their family members were 279 in heterozygotic state and not found in unaffected.

280

281 Angiotensin-1-Converting Enzyme Gene Polymorphism

282 The present study reports on the molecular screening of a population of 109 unrelated 283 index patients and 100 controls. Mutational screening was performed in one modifier gene Angiotensin-1-converting enzyme (ACE) i.e., zinc metallopeptidase widely distributed on the surface of endothelial and epithelial cells (27). When in demand, renin activity leads to the conversion of angiotensinogen to angiotensin I. ACE then converts angiotensin I to angiotensin II, which have been implicated in the modulation of cardiac 288 growth (28). The human ACE gene is located on chromosome $17 q 23$ and includes 26 289 exons. Polymorphism involving the presence (insertion I/I) or absence (deletion D/D) of a 290 287-basepair sequence of DNA in intron 16 of this modifier gene, encoding for ACE with 291 differences in plasma ACE levels is examined in Cardiomyopathy patients (29). Table 4 
illustrates variation in the genotype and allele frequency of the patient and control. Most notably the deletion homozygotes found to be higher in the patients. Also, the percent of heterozygote varied significantly among the two groups. Similarly, the deletion allele frequency was considerably higher in patients about $60 \%$ than controls $(44 \%)$. The chi square value in patients and controls was 0.109 and 1.148 respectively.

The genotypes DD vs ID, DD vs II, ID vs II, DD + ID vs II, DD vs ID + II and D vs I was taken for the odds ratio comparison. All the odds ratio values were higher than the threshold value of 1 . The odds ratio was highest for the genotype DD vs II (3.82) with a X2 value of 10.59 . This was followed by DD + ID vs II and ID vs II genotypes having an odds ratio of $2.79\left(x^{2}=8.60\right)$ and $2.27\left(x^{2}=4.48\right)$ respectively. The DD vs ID genotype comparison had an odds ratio of $0.60\left(x^{2}=1.94\right)$. It should be noted that the $x^{2}$ value is taken to evaluate the significance of the genotypes. Patients with $\mathrm{D}$ allele tend to be a higher risk and modify the disease pattern when compared with I allele. The odds ratio was found out to be 1.14 with a $x 2$ value 12.09. In Table 5 the chi square and the odds ratio values were calculated to prove the significance of the genotype of patients and reference to the control.

\section{DISCUSSION}

Cardiomyopathies are diseases of the heart muscle and a cause of concern. They exhibit a wide spectrum in disease onset, manifestation as well as in progression (30). Significant differences were observed for age and sex ratio between control and patients with 
cardiomyopathy. Mean age of diagnosis was higher in the patient data of the present study than in studies of HCM and DCM previously reported $(31,32)$. This may be due to mutation carriers screened in a predictive setting represent an asymptomatic subgroup within the total population of affected. Besides age, gender was an important cofactor in the clinical manifestation of HCM and DCM (33). The cardiomyopathy patients of the present study were characterized with significant increase in atrial natriuretic peptide and brain natriuretic peptide, which were correlated with left ventricular ejection fraction, mean pulmonary arterial pressure and pulmonary artery wedge pressure. Present data provides evidence that ANP and BNP are the best indicators for heart failure in cardiomyopathy patients. An elevated mean diastolic blood pressure $(81.41 \pm 4.76)$ and systolic blood pressure $(125.0 \pm 9.17)$ were observed in cardiomyopathy patient's data of the present study. A higher diastolic and systolic blood pressure has been observed in Caucasians (34), Chinese (35) and Japanese (36) origin.

Phospholamban is an inhibitor of endogenous sarcoplasmic reticulum calcium ATPase in dephosphorylated condition. It plays a regulatory role in the calcium handling during the process of cardiac contraction/relaxation. Mutations in this gene shown to associate with elevated cytosol calcium concentration. Phospholamban is phosphorylated by protein kinase $A$ to increase the reuptake of calcium into sarcoplasmic reticulum $(37,38,39)$.

Besides dilated cardiomyopathy though this is the first report to show Phospholamban gene mutation associated with hypertrophic cardiomyopathy, none of the all identified mutations falls neither within the coding region nor at conserved domain. Similar to this study there are few other studies had shown flanking regions and promoter variants of PLN associated with DCM/heart failure and $\operatorname{HCM}(40,41)$. Alternatively, there are reports 
that show no associations $(42,43)$. It is possible that PLN gene mutations can express at a lower level leading to a smaller pathogenic effect during sixth decade of life in these individuals. Contrastingly two familial cases showed mutation of PLN (4887 T/G) possibly decrease the transcriptional activity of promoter and associated with hypertrophic cardiomyopathy.

The mutation that is located near the promoter region has been defined as the fragment with maximal transcriptional activity (44). The increase or the decrease in phospholamban activity due to the disruption around the promoter region can lead to cardiomyopathy (41). Some carriers do not exhibit clinical conditions and mutation may be due to other genetic and environmental factors. This study concludes that PLN gene mutations are not frequent cause of hypertrophic or dilated cardiomyopathy in Indian population.

Although similar data were lacking, it was observed that Indians show a greater variation and this may be due to the polymorphism in ACE gene (modifier gene). Further, role of a dual peptide system viz., brain, and atrial natriuretic peptides in sodium balance and blood pressure regulation in those patients cannot be ruled out (45). Angiotensin-1-converting enzyme gene insertion/deletion (I/D) polymorphism is considered as an important modifier gene, which may influence the clinical phenotype of the cardiovascular disorders (46). The present data revealed that the frequencies of the DD genotype and D allele were significantly higher in patients compared with controls, and were associated with increased risk of $\mathrm{HCM}$ and DCM. Furthermore, regression analysis revealed that the genotypes DD and D allele were independent risk factors for these cardiomyopathies in Indian population. Patients with the DD genotype had the highest odds ratio of disease susceptibility and the subjects with II genotype have a lower risk of developing 
cardiomyopathies that may possibly through a cardio protective effect. The $\mathrm{D}$ allele compared with I allele has more than 25 percent increased risk to cardiomyopathy. On comparison, the prevalence of D allele in the present study (Indian population) was slightly higher (about $60 \%$ ) than Tunisian and Turkish populations $(47,48)$. Association of DD genotype / D allele with HCM and DCM have been reporting in many studies $(49,50)$ and the polymorphism considered as a modifier gene marker to cardiomyopathy. The DD genotype was also found to be associated with hypertension, restenosis, diabetes and myocardial infarction $(51,52)$. However, absences of association $(53,54)$ or influencing the cardiac phenotype (55) were reported in few other studies. These variations were partly accounted for ethnicity of the patients and to the sampling of the patients $(56,57)$.

\section{CONCLUSION:}

Among the two types of cardiomyopathies; dilated cardiomyopathy (73\%) was found to be most predominant, whereas hypertrophic cardiomyopathy accounts for $27 \%$. In general, increased male predominance $(73 \%)$ was observed in both the types of cardiomyopathies. Familial occurrence was in $24 \%$ of the patients, parental consanguinity was $14 \%$ and $30 \%$ had family history of sudden cardiac death. Diastolic blood pressure of the cardiomyopathy patients was significant $(p<0.05)$ than the systolic blood pressure and heart rate. Also, they were characterized with higher Atrial Natriuretic Peptide and Brain Natriuretic Peptide $(p<0.001)$. Contrastingly co-morbid factors and other enzymes did not show much influence between patients and control subjects. Mutation screening of phospholamban gene revealed two transitions (4880 C/T, $4887 \mathrm{~T} / \mathrm{G})$ in $5^{\prime}$ flanking region. Among them 4887 T/G transition was inherited in a hypertrophic cardiomyopathy 
patient's family. Two transitions (5073 T/G, 5076 A/T) in exon 1 and two transitions (15507 C/G, $15516 \mathrm{~T} / \mathrm{C}$ ) and an insertion (15512 T ins) in intron 1 were observed. Mutations located near to the promoter region have been defined as the fragment with maximal transcriptional activity. Mutations of this gene cause inherited dilated cardiomyopathy with refractory congestive heart failure. The protein is involved in blood circulation, and calcium ion transportation. No mutations occurred in the coding region of this gene so there is no change in the protein sequence consequently. Mutations located close to the promotor region have been defined as the fragment with maximal transcriptional activity. The increase or decrease in phospholamban activity due to the disruption around the promoter region can lead to cardiomyopathy. No mutations were observed in control subjects. Further, the deletion allele frequency of angiotensin-1- converting enzyme was considerably higher in cardiomyopathy patients $(61.5 \%)$ than the control subjects $(44 \%)$.

\section{Availability of data and materials:}

All data relevant to the findings are available in this paper. We are bound by the participant consent which precludes data deposition in repositories. Further nonidentifiable data is available upon request to Dr. N. Gnana Veera Subhashini

\section{(dr.ngvsubhashini@bcgrc.com)}

\section{Funding}

This work was Self-funded.

All data generated or analyzed during this study are included in this published article.

\section{Authors' contributions}


407

408

409

410

411

412

413

414

415

416

417

GVS, MJ, BSL, EC and KMC made substantial contributions to conception and design of the experiments, or to acquisition, analysis, or interpretation of the data; GVS, EC and $\mathrm{KMC}$ were involved in drafting or critically revising the manuscript for important intellectual content; BSL and GVS gave final approval of the version to be published. All authors agree to be accountable for all aspects of the work, and will ensure that questions related to the accuracy or integrity of any part of the work are appropriately investigated and resolved. All authors read and approved the final manuscript.

\section{Consent for publication}

The authors declare that they have received consent from study subjects/Participants for publication.

\section{Competing interests}

The authors declare that they have no competing interests in relation to this manuscript or this study.

\section{REFERENCES:}

1 Towbin, Jeffrey A. "Inherited Cardiomyopathies." Circulation Journal, vol. 78, no. 10, 2014, pp. 2347-2356., doi:10.1253/circj.cj-14-0893

2 Maron, B J. "Contemporary Considerations for Risk Stratification, Sudden Death and Prevention in Hypertrophic Cardiomyopathy." Heart, vol. 89, no. 9, 2003, pp. 977-978., doi:10.1136/heart.89.9.977.

3 Jacoby, D., and W. J. Mckenna. "Genetics of Inherited Cardiomyopathy." European Heart Journal, vol. 33, no. 3, 2011, pp. 296-304., doi:10.1093/eurheartj/ehr260. 
4294 Vinten-Johansen, Jakob, et al. "Inflammation, Proinflammatory Mediators and 430 Myocardial Ischemiaâ Reperfusion Injury." Hematology/Oncology Clinics of North 431 America, vol. 21, no. 1, 2007, pp. 123-145., doi:10.1016/j.hoc.2006.11.010.

4325 Codd MB, Sugrue DD, Gersh BJ. Epidemiology of idiopathic dilated and hypertrophic 433 cardiomyopathy. A population-based study in Olmsted County, Minnesota, 1975-1984. 434 Circulation. 1989; 80(3):564-72.

4356 Maron BJ, Wolfson JK, Epstein SE, Roberts WC. Intramural ("small vessel") coronary 436 artery disease in hypertrophic cardiomyopathy. J Am Coll Cardiol. 1986; 8(3):545-57

4377 Schwartz. W.M; Louis M Bell Jr., Peter M Bingham; Esther K Chung

438 et al., The 5-Minute Pediatric Consult, Fifth Edition, Lippincott Williams \& Wilkins, March 439 2008; ISBN 0-7817-7577-9

4408 Hershberger, Ray E, et al. "Clinical and Genetic Issues in Dilated Cardiomyopathy: A 441 Review for Genetics Professionals." Genetics in Medicine, vol. 12, no. 11, 2010, pp. 655442 667., doi:10.1097/gim.0b013e3181f2481f.

443 9. Meyer, Sven, et al. "Sex Differences in Cardiomyopathies." European Journal of Heart 444 Failure, Wiley-Blackwell, 16 Jan. 2014, onlinelibrary.wiley.com/doi/10.1002/ejhf.15/full. 445 10. Maron BJ, Wolfson JK, Epstein SE, Roberts WC. Intramural ("small vessel") coronary 446 artery disease in hypertrophic cardiomyopathy. J Am Coll Cardiol. 1986; 8(3):545-57 447 11. McMurray, John J. V., et al. "Baseline Characteristics and Treatment of Patients in 448 Prospective Comparison of ARNI with ACEI to Determine Impact on Global Mortality and 449 Morbidity in Heart Failure Trial (PARADIGM-HF)." European Journal of Heart Failure, 450 Wiley-Blackwell, 3 June 2014, onlinelibrary.wiley.com/doi/10.1002/ejhf.115/abstract. 
451 12. Bui, A L, et al. "Epidemiology and Risk Profile of Heart Failure." Nature Reviews.

452 Cardiology., U.S. National Library of Medicine, Jan. 2011,

453 www.ncbi.nlm.nih.gov/pubmed/21060326.

454 13. Oxenoid, K., Chou, J. J. The structure of phospholamban pentamer reveals a channel-

455 like architecture in membranes. Proc. Nat. Acad. Sci. 2005; 102: 10870-10875

456 14. McTiernan, C. F., Frye, C. S., Lemster, B. H., Kinder, E. A., Ogletree-Hughes, M. L., 457 Moravec, C. S., Feldman, A. M. The human phospholamban gene: structure and 458 expression. J. Molec. Cell Cardiol. 1999; 31: 679-692

459 15. MacLennan, D.H., Kranias, E.G. Phospholamban: a crucial regulator of cardiac 460 contractility. Nat Rev Mol Cell Biol 2003; 4: 566-577.

461 16. Schmitt JP, Kamisago M, Asahi M, Li GH, Ahmad F, Mende U, Kranias EG, 462 MacLennan DH, Seidman JG, Seidman CE. Dilated cardiomyopathy and heart failure 463 caused by a mutation in phospholamban. Science. 2003; 299:1410-1413.

464 17. Eric. "Susceptibility Genes and Modifiers for Cardiac Arrhythmias | Cardiovascular 465 Research | Oxford Academic." OUP Academic, Oxford University Press, 15 Aug. 2005, 466 academic.oup.com/cardiovascres/article/67/3/397/505703/Susceptibility-genes-and467 modifiers-for-cardiac.

468 18. Fatkin1, Diane, and Christine E. Seidman4. "Diane Fatkin." Cold Spring Harbor 469 Perspectives in Medicine, 1970 , 470 perspectivesinmedicine.cshlp.org/lookup/doi/10.1101/cshperspect.a021063.

471 19. Marian, AJ. "Modifier Genes for Hypertrophic Cardiomyopathy." Current Opinion in 472 Cardiology, europepmc.org/articles/PMC2775140. 
473 20. Rudnicki, Michael, and Gert Mayer. "Significance of Genetic Polymorphisms of the

474 Reninâ Angiotensinâ Aldosterone System in Cardiovascular and Renal 475 Disease." Pharmacogenomics, vol. 10, no. 3, 2009, pp. 463-476., 476 doi:10.2217/14622416.10.3.463.

477 21. Charron $\mathrm{P}$, Komajda $\mathrm{M}$. Are we ready for pharmacogenomics in heart failure? Eur $\mathrm{J}$ $478 \quad$ Pharmacol. 2001; 417:1-9

479 22. Heribert Schunkert, Hans-Werner Hense, Stephan R et al., "Association between a 480 Deletion Polymorphism of the Angiotensin-Converting-Enzyme Gene and Left Ventricular 481 Hypertrophy NEJM." New England Journal of Medicine, $482 \quad$ www.nejm.org/doi/10.1056/NEJM199406093302302.

483 23. Lahiri DK, Schnabel B. DNA isolation by a rapid method from human blood samples: 484 effects of $\mathrm{MgCl}$, EDTA, storage time, and temperature on DNA yield and quality. $485 \quad$ Biochem Genet. 1993; 31: 321-328.

486 24. Susumu Minamisawa, Yoji Sato, Yuriko Tatsuguchi, Tomofumi Fujino, Shinichiro 487 Imamura, Yoshio Uetsuka, Makoto Nakazawa and Rumiko Matsuoka. Mutation of the 488 phospholamban promoter associated with hypertrophic cardiomyopathy Biochemical and 489 Biophysical Research Communications. 2003; 304.

490 25. Rigat, B., Hubert, C., Alhenc-Gelas, F et al., An insertion/deletion polymorphism in

491 the angiotension I-converting enzyme gene accounting for half the variance of serum 492 enzyme levels. J. Clin. Invest., 1990; 86, 1343-1346.

493 26. Zhang, Ling, et al. "Interaction of Angiotensin I-Converting Enzyme Insertion-Deletion 494 Polymorphism and Daily Salt Intake Influences Hypertension in Japanese 
495 Men." Hypertension Research, vol. 29, no. 10, 2006, pp. 751-758., 496 doi:10.1291/hypres.29.751.

497 27. RÃcken, Christoph, et al. "The Gene Polymorphism of the Angiotensin I-Converting 498 Enzyme Correlates with Tumor Size and Patient Survival in Colorectal Cancer 499 Patients." Neoplasia, vol. 9, no. 9, 2007, pp. 716-722., doi:10.1593/neo.07418.

500 28. Sparks, Matthew A., et al. "Classical Renin-Angiotensin System in Kidney 501 Physiology." Comprehensive Physiology, 2014, pp. 1201-1228., 502 doi:10.1002/cphy.c130040.

503 29. Leońska-Duniec, A, et al. Biology of Sport, Institute of Sport in Warsaw, Sept. 2016, 504 www.ncbi.nlm.nih.gov/pmc/articles/PMC4993135/.

505 30. Sisakian, Hamayak. "Cardiomyopathies: Evolution of Pathogenesis Concepts and 506 Potential for New Therapies." World Journal of Cardiology, Baishideng Publishing Group 507 Inc., 26 June 2014, www.wjgnet.com/1949-8462/full/v6/i6/478.htm.

508 31. Elliott PM et al. Sudden death in hypertrophic cardiomyopathy: identification of high 509 risk patients. J Am Coll Cardiol. 2000; 36: 2212-2218

510 32. Biagini $\mathrm{E}$ et al. Dilated-hypokinetic evolution of hypertrophic cardiomyopathy: 511 prevalence, incidence, risk factors, and prognostic implications in pediatric and adult 512 patients. J Am Coll Cardiol. 2005; 46: 1543-1550

513 33. Christiaans I, Erwin Birnie, Irene M. van Langen et al, The yield of risk stratification 514 for sudden cardiac death inhypertrophic cardiomyopathy myosin-binding protein $\mathrm{C}$ gene 515 mutation carriers: focus on predictive screening. Eur Heart J. 2010; 31 (7): 842-848.

516 34. Rossi A, Cicoira M, Golia G, Anselmi M, Zardini P. Mitral regurgitation and left 
ventricular diastolic dysfunction similarly affects mitral and pulmonary vein flow Doppler parameters: the advantage of end-diastolic markers. J Am Soc Echocardiogr. 2001; 14(6):562-8.

35. Fung DC, Yu B, Littlejohn T, Trent RJ. An online locus-specific mutation database for familial hypertrophic cardiomyopathy. Hum Mutat. 1999; 14: 326-32.

36. Sugimoto K, Katsuya T, Ohkubo T, Hozawa A et al, Association between angiotensin II type 1 receptor gene polymorphism and essential hypertension: the Ohasama Study. Hypertens Res. 2004; 27(8):551-6.

37. Kranias EG, Bers DM. Calcium and cardiomyopathies. Subcell Biochem, 2007; 45: $523-537$.

38. Traaseth NJ, et al. Structural and dynamic basis of phospholamban and sarcolipin inhibition of ca(2+)-ATPase. Biochemistry. 2008; 47:3-13.

39. Vafiadaki E, Demetrios A. Arvanitis, Stamatis N. Pagakis, Vasiliki Papalouka, Despina Sanoudou, Aikaterini Kontrogianni-Konstantopoulos and Evangelia G. Kranias. The Antiapoptotic Protein HAX-1 Interacts with SERCA2 and Regulates Its Protein Levels to Promote Cell Survival. Mol. Biol. Cell. 2009; vol. 20 no. 1 306-318.

40. Medin M, Hermida-Prieto M, Monserrat L, Laredo R, Rodriguez-Rey JC, Fernandez X, Castro-Beiras A.Mutational screening of phospholamban gene in hypertrophic and idiopathic dilated cardiomyopathy and functional study of the PLN $-42 \mathrm{C}>\mathrm{G}$ mutation. Eur J Heart Fail. 2007; Jan; 9(1): 37-43.

41. Haghighi K, Chen G, Sato Y, Fan GC, He S, Kolokathis F, Pater L, Paraskevaidis I, Jones WK, Dorn GW 2nd, Kremastinos DT, Kranias EG. A human phospholamban 
539

540

541

promoter polymorphism in dilated cardiomyopathy alters transcriptional regulation by glucocorticoids. Hum Mutat. 2008; (5):640-7.

42. Kalemi T, Efthimiadis G, Zioutas D, Lambropoulos A, Mitakidou A, Giannakoulas G, Vassilikos V, Karvounis H, Kotsis A, Parharidis G and Louridas G. Phospholamban gene mutations are not associated with hypertrophic cardiomyopathy in a Northern Greek population. Biochem Genet. 2005; 43(11-12):637-42

43. Santos GB Diogo, Alessandra Medeiros,Patrícia C Brum, José G Mill, Alfredo J Mansur, José E Krieger and Alexandre C Pereira. No evidence for an association between the $-36 \mathrm{~A}>\mathrm{C}$ phospholamban gene polymorphism and a worse prognosis in heart failure. BMC Cardiovasc Disord. 2009; 9: 33.

44. Simmerman, H. K. B., and L. R. Jones. Phospholamban: protein structure, mechanism of action, and role in cardiac function. Physiol. Rev. 1998; 78:921-947

45. Buckley MG, Markandu ND, Sagnella GA, MacGregor GA. Brain and atrial natriuretic peptides: a dual peptide system of potential importance in sodium balance and blood pressure regulation in patients with essential hypertension. J Hypertens. 1994; 27:80913.

46. Candy GP, Skudicky D, Mueller UK, Woodiwiss AJ et al., Association of left ventricular systolic performance and cavity size with angiotensin-converting enzyme genotype in idiopathic dilated cardiomyopathy. Am J Cardiol. 1999; 83: 740-4. 
47. Rai TS, Dhandapany PS, Ahluwalia TS et al. ACE I/D polymorphism in Indian patients with hypertrophic and dilated cardiomyopathy. Molecular and cellular biochemistry 2008; 311(1-2): 67-72.

48. Mahjoub S, Mehri S, Bousaada R, Ouarda F, Zaroui A et al, Association of ACE I/D polymorphism in Tunisian patients with dilated cardiomyopathy. Journal of ReninAngiotensin-Aldosterone System. 2010 vol. 11 no. 3 187-191.

49. Raynolds MV, Bristow MR, Bush EW, Abraham WT et al, Angiotensin-converting enzyme DD genotype in patients with ischaemic or idiopathic dilated cardiomyopathy. Lancet. 1993; 342:1073-1075.

50. Kawaguchi $H$. Angiotensin-converting enzyme and angiotensinogen gene polymorphism in hypertrophic cardiomyopathy. Exp Clin Cardiol. 2003; 8(3): 155-159.

51. Dzau, V. J. Cell biology and genetics of angiotensin in cardiovascular disease. J. Hypertens. 1994; 12, 3-10.

52. Gardemann, A., Fink, M., Sticker, J., Nguyen, Q. D., Humme, J., Katz, N et al., ACE I/D polymorphism: presence of the ACE D allele increases the risk of coronary artery disease in younger individuals. Atherosclerosis. 1998; 139, 153-159.

53. Montgomery HE, Keeling PJ, Goldman JH, Humphries SE, Talmud PJ, McKenna WJ. Lack of association between the insertion/deletion polymorphism of the angiotensin converting enzyme gene and idiopathic dilated cardiomyopathy. J Am Coll Cardiol. 1995; 25:1627-1631.

54. Yamada Y, Ichihara S, Fujimura T, Yokota M. Lack of association of polymorphisms of the angiotensin converting enzyme and angiotensinogen genes with nonfamilial hypertrophic or dilated cardiomyopathy. Am J Hypertens 1997; 10: 921-928. 
581 55. Mahjoub S, Mehri S, Bousaada R, et al. Association of ACE I/D polymorphism in 582 Tunisian patients with dilated cardiomyopathy. Journal of the Renin-Angiotensin583 Aldosterone system. 2011; 11(3): 187-191.

584 56. Wang, P., Zou, Y., Fu, C. Y., Zhou, X., Hui, R. MYBPC3 polymorphism is a modifier 585 for expression of cardiac hypertrophy in patients with hypertrophic cardiomyopathy. 586 Biochem. Biophys. Res. Commun. 2005; 329: 796-799.

587 57. Pfohl, M., Koch, M., Prescod, S., Haase, K. K., Haring, H. U. and Karsch, K. R.

588 Angiotensin I- converting enzyme gene polymorphism, coronary artery disease and 589 myocardial infarction. An angiographic ally controlled study. Eur. Heart J. 1999; 20, 1318$590 \quad 1325$.

594 Table 1. Baseline, Hemodynamic and Biochemical Characteristics

\begin{tabular}{|l|l|l|l|}
\hline Characteristics & Cases $\mathbf{n = 1 0 9}$ & $\begin{array}{l}\text { Control } \\
\mathbf{n = 1 0 0}\end{array}$ & $\begin{array}{l}\text { Cases vs Control P } \\
\text { value }\end{array}$ \\
\hline Age, Yrs & $37.22 \pm 12.43$ & $40 \pm 12.65$ & 0.111 \\
\hline Gender & \multicolumn{2}{|l|}{$0.034^{*}$} \\
\hline Male, $\mathbf{n}$ & 73 & 52 & \\
\hline Female, n & 36 & 48 & 0.386 \\
\hline Parental Consanguinity, $\mathbf{n}$ & $15(13.76)$ & 9 & 0.085 \\
\hline (\%) & & $23.76 \pm 3.33$ & \\
\hline BMI (kg/m2) & $24.65 \pm 4.08$ & 23 & \\
\hline
\end{tabular}




\begin{tabular}{|c|c|c|c|}
\hline BSA (m2) & $1.79 \pm 0.17$ & $1.84 \pm 0.75$ & 0.515 \\
\hline Sys BP (mmHg) & $125.0 \pm 9.17$ & $120.0 \pm 14$ & $0.003^{*}$ \\
\hline Dys BP(mmHg) & $81.41 \pm 4.76$ & $78.0 \pm 10.0$ & $0.002^{*}$ \\
\hline Heart Rate (beats/min) & $74.06 \pm 4.08$ & $72.3 \pm 4.5$ & $0.004^{*}$ \\
\hline Familial status, $\mathbf{n}(\%)$ & $26(23.85)$ & & \\
\hline F/H of SCD, $n(\%)$ & $33(30.28)$ & & \\
\hline \multicolumn{4}{|l|}{ NYHA } \\
\hline Class I, II, n \%) & $37(33.94)$ & & \\
\hline Class III, IV, n (\%) & $72(66.06)$ & & \\
\hline ANP (pg/ml)) & $\begin{array}{ll}130.21 \quad \pm \\
24.67\end{array}$ & $21.9 \pm 17.6$ & $<0.001$ \\
\hline BNP (pg/ml) & $\begin{array}{l}110.36 \\
\pm 110.12\end{array}$ & $8.12 \pm 8.08$ & $<0.001$ \\
\hline CpK $\geq 37$ U/L, n (\%) & $26(23.85)$ & 21 & 0.74 \\
\hline SGOT $\geq 13 U / L, n(\%)$ & $35(32.11)$ & 20 & 0.059 \\
\hline SGPT $\geq 17 \mathrm{U} / \mathrm{L}, \mathrm{n}(\%)$ & $32(29.36)$ & 30 & 1 \\
\hline Glucose (mg/dl)) & $96.16 \pm 8.0$ & $95 \pm 7$ & 0.265 \\
\hline Urea (mg/dl) & $27.36 \pm 2.29$ & $27.92 \pm 4.12$ & 0.232 \\
\hline Creatinine (mg/dl) & $0.90 \pm 0.32$ & $0.84 \pm 0.19$ & 0.098 \\
\hline HTN, n (\%) & $31(28.44)$ & 17 & 0.07 \\
\hline DM, n (\%) & $39(35.78)$ & 27 & 0.183 \\
\hline Obesity, n (\%) & $22(20.18)$ & 21 & 1 \\
\hline
\end{tabular}




\begin{tabular}{|c|c|c|c|}
\hline $\begin{array}{l}\text { Current ad Ex-Smokers, } n \\
(\%)\end{array}$ & $64(58.72)$ & 72 & 0.059 \\
\hline $\begin{array}{l}\text { Current and Ex- } \\
\text { Alcoholics, } \mathrm{n}(\%)\end{array}$ & $54(49.54)$ & 56 & 0.406 \\
\hline
\end{tabular}

597 Data shown as Mean \pm Standard deviation or number or number (\%) F/H of SCD- Family 598 history of sudden cardiac death, BMI- Body mass index, BSA- Body surface area, sys 599 BP, Dys BP systolic, diastolic blood pressure, NYHA- New York heart association 600 functional class, ANPAtrial natriuretic peptide, BNP- Brain natriuretic peptide, CpK601 Creatine phosphokinase, SGOTSerum Aspartate transaminase, SGPT- Serum alanine 602 transaminase, HTN- Hypertension, DMDiabetes Mellitus. P value is probability of chi603 square with one degree of freedom of genotype frequencies in control and case datasets. $604{ }^{*}$ Pvalue $<0.05,{ }^{* *}$ Pvalue $<0.01,{ }^{* * *}$ Pvalue $<0.001$.

605

Table 2 Clinical characteristics of Patients and control

\begin{tabular}{|l|l|l|l|}
\hline Characteristics & DCM & HCM & Control \\
& $\mathbf{n = 8 0 + 4 7 = 1 2 7}$ & $\mathbf{n = 2 9 + 2 3 = 5 2}$ & $\mathbf{n = 1 0 0}$ \\
\hline LVESD(mm) & $46.0 \pm 6^{* * *}$ & $26 \pm 7^{* * *}$ & $31 \pm 5$ \\
\hline LVEDD(mm) & $71.5 \pm 2^{* * *}$ & $69 \pm 7^{* * *}$ & $52 \pm 3$ \\
\hline LVEF (\%) & $65 \pm 6^{* * *}$ & $36 \pm 7^{* * *}$ & $53 \pm 7$ \\
\hline FS (\%) & $39 \pm 7^{* *}$ & $38 \pm 8$ & $36 \pm 7$ \\
\hline IVST(mm) & $18 \pm 6^{* * *}$ & $11 \pm 3^{* * *}$ & $8 \pm 2$ \\
\hline
\end{tabular}




\begin{tabular}{|c|c|c|c|}
\hline PWT(mm) & $22 \pm 5^{\star * \star}$ & $12 \pm 2^{* * *}$ & $8 \pm 2$ \\
\hline LVMI (gm/m2) & $106 \pm 25^{\star \star *}$ & $106 \pm 49^{* * *}$ & $61 \pm 30$ \\
\hline $\begin{array}{l}\text { LV Volume/mass } \\
\text { ratio (mL/gm) }\end{array}$ & $0.77 \pm 0.6^{* * *}$ & $0.18 \pm 0.1^{* * *}$ & $0.30 \pm 0.07$ \\
\hline LVESV (ml) & $127 \pm 61^{* * *}$ & $38 \pm 17^{*}$ & $32 \pm 11$ \\
\hline LVEDV (ml) & $179 \pm 7^{* \star *}$ & $103 \pm 37^{*}$ & $86 \pm 24$ \\
\hline $\begin{array}{l}\text { LVOT } \\
\text { gradient }>20 \mathrm{mmHg} \text {, } \\
\mathrm{n}(\%)\end{array}$ & $96(75.59)$ ** & $39(75)$ & 57 \\
\hline E/A ratio & $1.7 \pm 1.1^{*}$ & $1.4 \pm 0.9$ & $1.3 \pm 1$ \\
\hline IVPG (mmHg) & $1.1 \pm 0.3^{* \star *}$ & $1.4 \pm 0.6^{*}$ & $1.6 \pm 0.4$ \\
\hline LAVI (ml/m2) & $38 \pm 14^{* * *}$ & $30 \pm 9^{* \star *}$ & $18 \pm 7$ \\
\hline QRS width (ms) & $145 \pm 11^{* * *}$ & $106 \pm 14^{\star \star *}$ & $91 \pm 16$ \\
\hline PR (ms) & $112 \pm 11^{* * *}$ & $101 \pm 9^{* * *}$ & $126 \pm 8$ \\
\hline Max QTc (ms) & $434 \pm 24^{* * *}$ & $455 \pm 26^{* \star *}$ & $400 \pm 25$ \\
\hline
\end{tabular}

607

608

609 Data shown as Mean \pm Standard deviation or number (\%) LVESD- Left Ventricular End 610 systolic diameter, LVEDD-Left ventricular end diastolic diameter, LVEF- Left ventricular 611 ejection fraction, FS- Fractional shortening, IVST- Inter ventricular septal thickness, PWT612 Posterior wall thickness, LVMI- Left ventricular mass index, LAVI- Left atrial volume index, 613 LVOT- Left ventricular outflow tract, E/A ratio- early-to-late transmitral flow velocity, IVPG614 Intraventricular pressure gradient. P value is probability of chi-square with one degree of 
615 freedom of genotype frequencies in control and case datasets. ${ }^{*}$ Pvalue $\leq 0.05,{ }^{* *}$ Pvalue $<$

$6160.01,{ }^{* * *}$ Pvalue $<0.001$

617

618 Table 3: Observed Nucleotide Changes in Phospholamban Gene

\begin{tabular}{|c|c|c|c|}
\hline Nucleotide changes & Loci & $\begin{array}{l}\text { Disease } \\
\text { type }\end{array}$ & Familial case \\
\hline $4880 \mathrm{C} / \mathrm{T}$ & 5' flanking region & DCM & No \\
\hline $4887 \mathrm{~T} / \mathrm{G}$ & 5' flanking region & $\mathrm{HCM}$ & Yes \\
\hline $5073 \mathrm{~T} / \mathrm{G}$ & Exon1 & DCM & No \\
\hline $5076 \mathrm{~A} / \mathrm{T}$ & Exon1 & DCM & No \\
\hline $15507 \mathrm{C} / \mathrm{G}$ & Intron1 & DCM & No \\
\hline 15512 ins $T$ & Intron1 & DCM & Yes \\
\hline $15516 \mathrm{~T} / \mathrm{C}$ & Intron1 & $\mathrm{DCM}$ & No \\
\hline
\end{tabular}

619

620 Table 4. Alu ACE1 Genotype and Allele frequencies in control and Patients with

621 cardiomyopathy 


\begin{tabular}{|l|l|l|l|l|l|l|}
\hline \multirow{2}{*}{ Subject } & \multicolumn{3}{|l|}{ Genotype } & \multicolumn{2}{l|}{ Allele Frequencies } & \multirow{2}{*}{$\mathfrak{x}^{2}$} \\
\cline { 2 - 6 } & II & ID & DD & I & D & \\
\hline Control & 34 & 44 & 22 & 0.56 & 0.44 & 1.148 \\
\hline Patients & 17 & 50 & 42 & 0.385 & 0.615 & 0.109 \\
& & & & & & \\
\hline
\end{tabular}

622

623

624

625

626

627 The present study investigates the association of spectrum of clinical symptoms and the

628 epidemiological variables like age, sex, familial status, and parental consanguinity. The 629 current study also evaluates Angiotensin-1-Converting Enzyme gene polymorphism and 630 its role as a marker / modifier in Cardiomyopathy.

Table 5. Frequency distribution of Alu ACE1 Genotype and allele frequency in Control and Patients of cardiomyopathy

\begin{tabular}{|c|c|c|c|c|c|}
\hline \multirow{2}{*}{$\begin{array}{ll}\text { Case Vs } \\
\text { Control }\end{array}$} & \multirow[t]{2}{*}{$x^{2}$} & \multirow{2}{*}{$\begin{array}{l}\mathbf{P} \\
\text { value }\end{array}$} & ODDs & \multicolumn{2}{|c|}{$95 \% \mathrm{Cl}$} \\
\hline & & & Ratio & & \\
\hline ID vs DD & 1.9358 & 0.1641 & 0.6 & 0.309 & 1.147 \\
\hline DD vs II & 10.589 & 0.0011 & 3.82 & 1.754 & 8.311 \\
\hline ID vs II & 4.4768 & 0.0344 & 2.27 & 1.118 & 4.619 \\
\hline DD + ID vs II & 8.6037 & 0.0034 & 2.79 & 1.437 & 5.408 \\
\hline DD vs ID + II & 5.9538 & 0.0147 & 2.22 & 1.207 & 4.092 \\
\hline D vs I & 12.088 & 0.0005 & 1.14 & 0.773 & 1.687 \\
\hline
\end{tabular}

631 
632 Figure 1: Chromatogram of Phospholamban Gene Mutation

633

634 (a) Representative Chromatograms showing $4880 \mathrm{C} / \mathrm{T}$
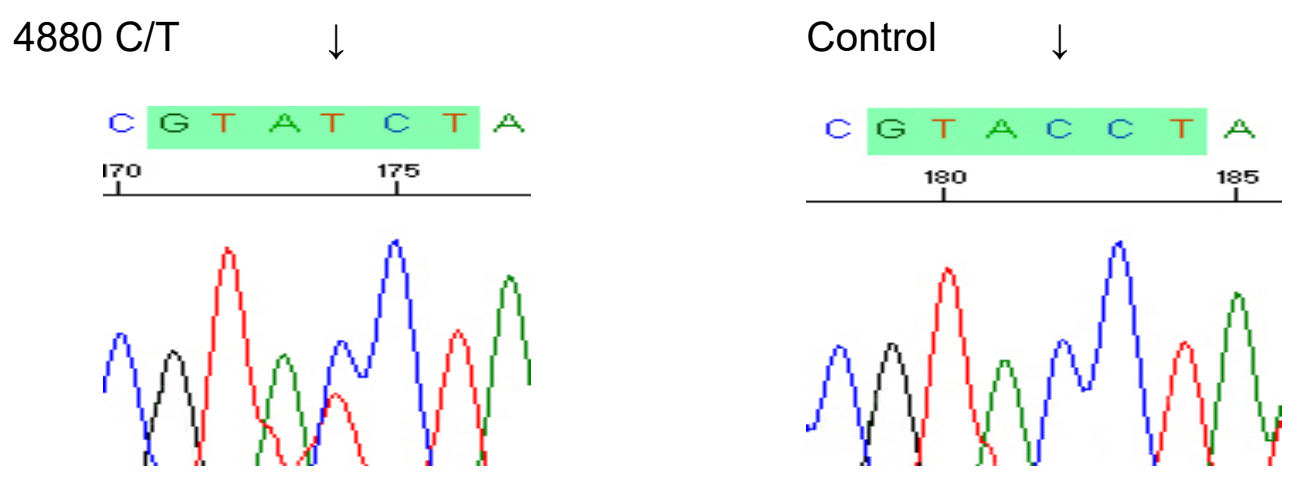

(b) Representative Chromatograms showing 4887 T/G

$4887 \mathrm{~T} / \mathrm{G}$

Control
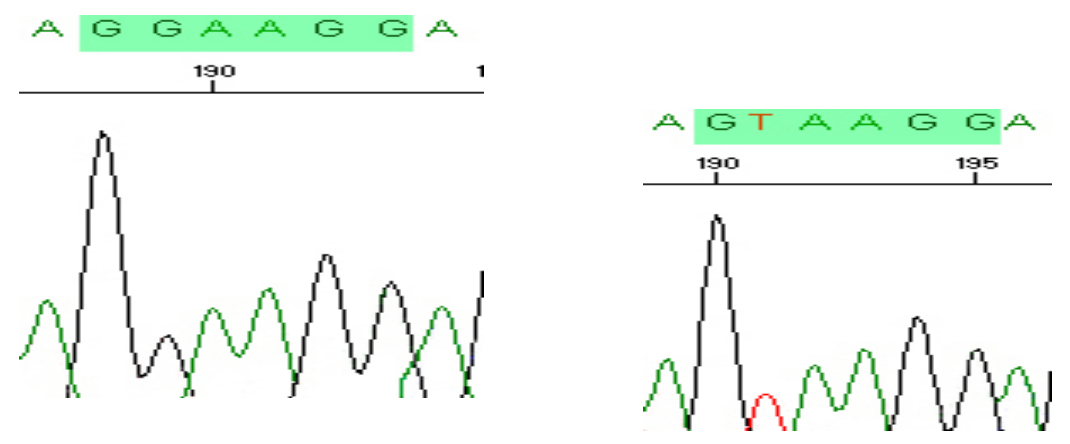
(C) Representative Chromatograms showing 5073 T/G, 5076 A/T

$5073 \mathrm{~T} / \mathrm{G}, 5076 \mathrm{~A} / \mathrm{T}$

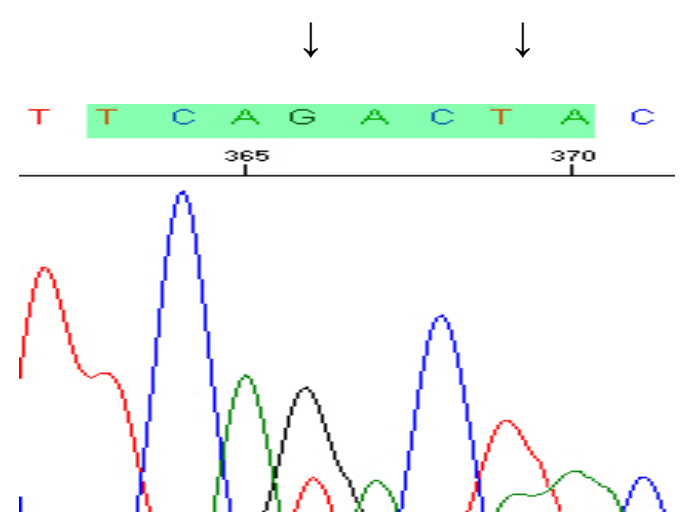

(d) Representative Chromatograms showing 15507 C/G
Control
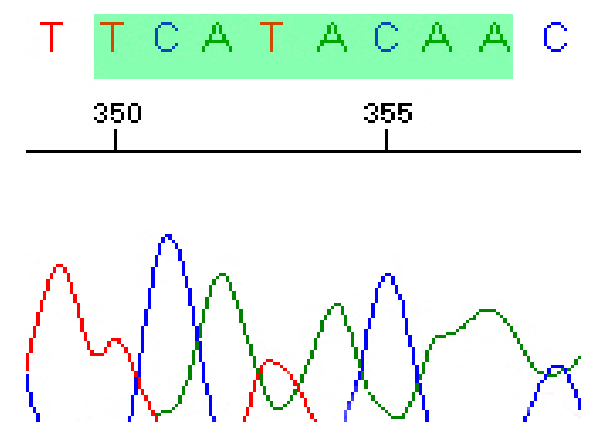
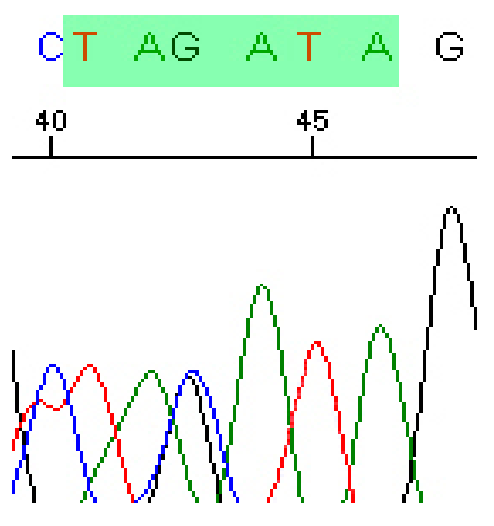

$15507 \mathrm{C} / \mathrm{G}$
Control $\downarrow$

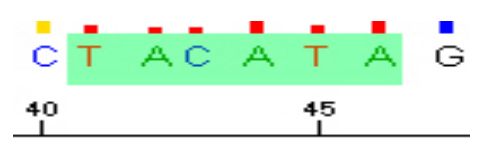

$m_{n}$ 
(e) Representative Chromatograms showing 15512 ins T
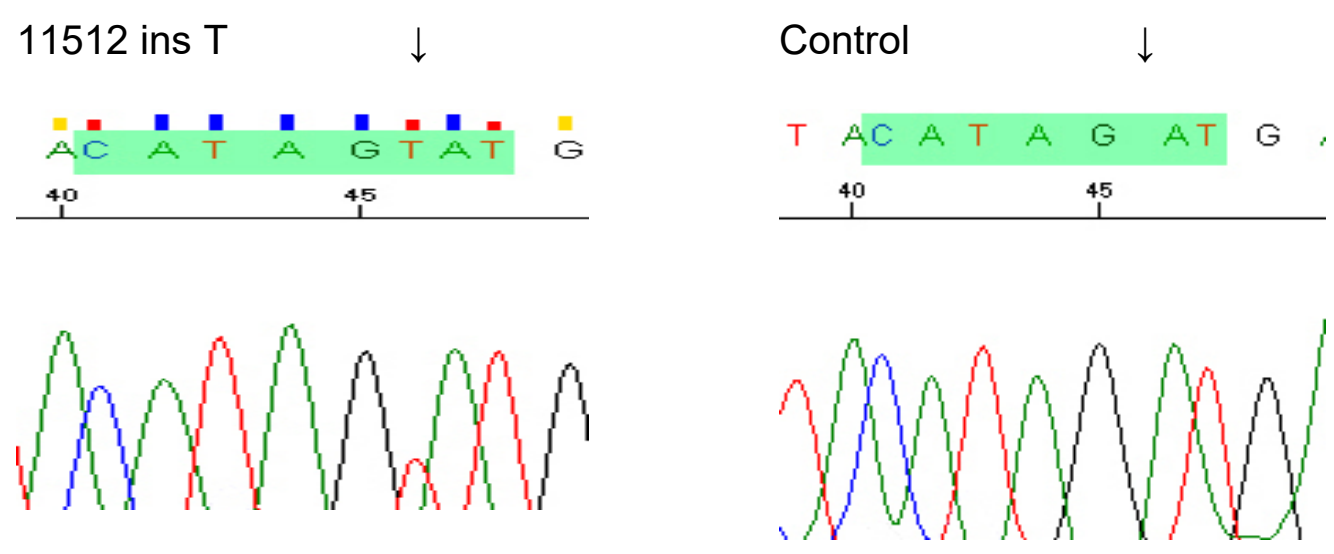

(f) Representative Chromatograms showing 15516 T/C

$15516 \mathrm{~T} / \mathrm{C}$

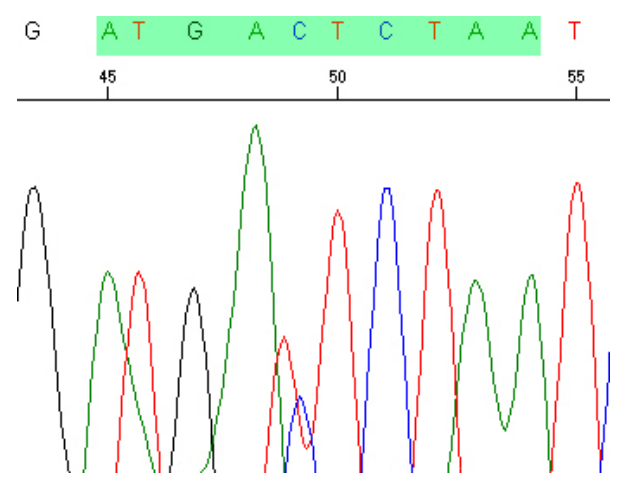

Control $\downarrow$

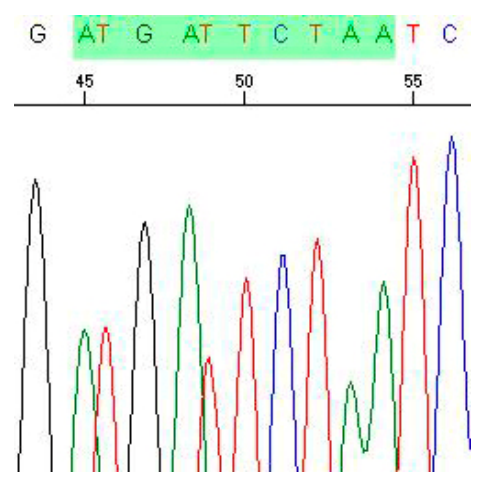

635

636

637

638

639 
640

641 Figure 2: Pedigree of H9 proband with $4887 \mathrm{~T} \rightarrow \mathrm{G}$ mutations in 5'flanking region of 642 PLN gene

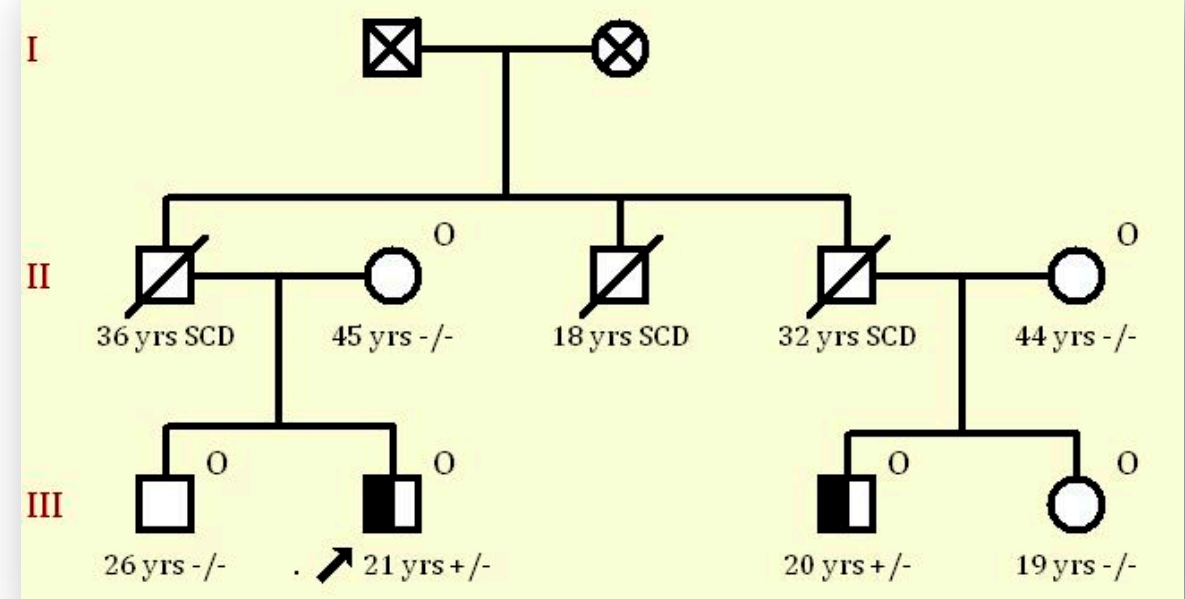

643

644 Figure 3: Pedigree of H10 proband with $4887 \mathrm{~T} \rightarrow \mathrm{G}$ mutations in 5'flanking region 645 of PLN gene

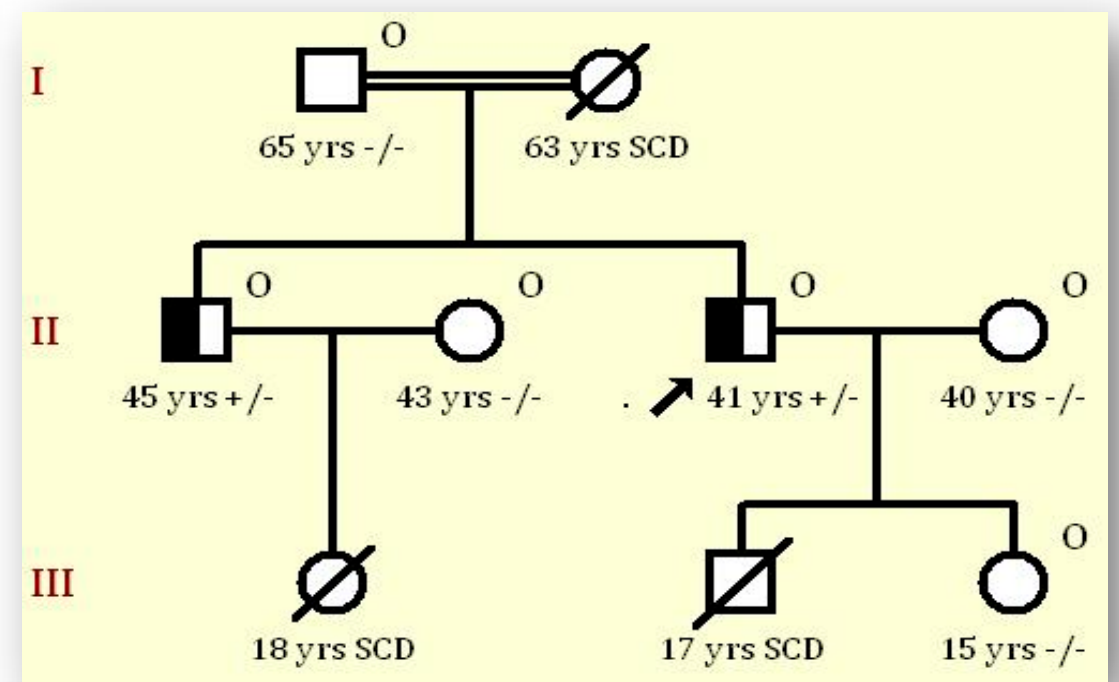

646 
647 Figure 4: Pedigree of D15 proband with 15512 ins T mutations in intron 1 of PLN 648 gene

649

650

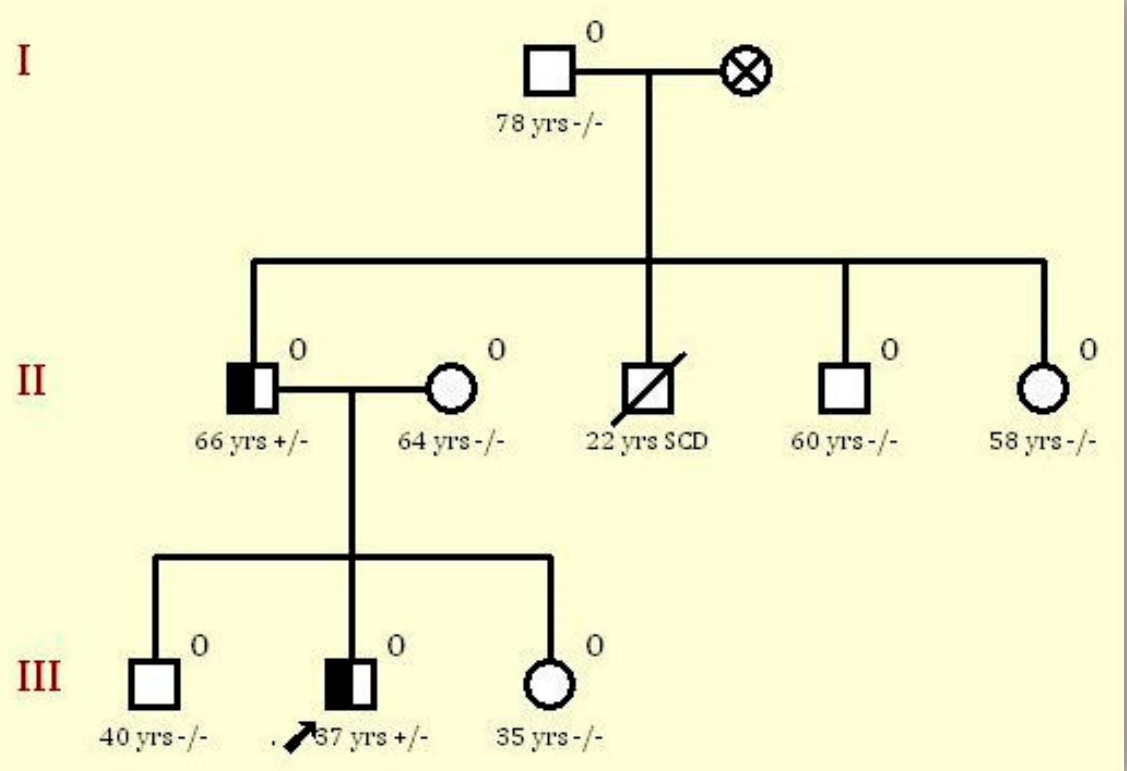

651

652 Note: +/- presence of mutation in heterozygote state; -/- absence of mutation; $\nearrow$ -

653 Proband;

654 o- Gene Sequenced; Age below each indicates age at investigation 